\title{
Vaginal stone formation secondary to vaginal tape exposure for stress urinary incontinence: a case report
}

\author{
Mandy $\mathrm{CH} \mathrm{Yu} \mathrm{*,} \mathrm{MB,} \mathrm{ChB,} \mathrm{FHKAM} \mathrm{(Obstetrics} \mathrm{and} \mathrm{Gynaecology)}$ \\ Department of Obstetrics and Gynaecology, United Christian Hospital, Kwun Tong, Hong Kong \\ *Corresponding author: cchhyu@yahoo.com \\ Hong Kong Med J 2019;25:401-2 \\ https://doi.org/10.12809/hkmj187211
}

\section{Case report}

A 57-year-old woman presented with a hard mass in the vagina. In 2009 she underwent a spiral sling procedure for severe stress incontinence. She had not attended postoperative follow-up examinations despite recurrence of stress incontinence symptoms around 18 months after surgery. She reported no pain or abnormal vaginal bleeding. Physical examination revealed a stone measuring around $3 \mathrm{~cm}$ along the right vaginal sulcus attaching to the exposed mesh.

Vaginal stone removal was performed under general anaesthesia. Dissection was done along the exposed mesh up to the retropubic space as far as possible (Fig). A total of $1.5 \mathrm{~cm}$ vaginal mesh was removed together with the stone. Cystoscopy was also performed to exclude any tape erosion or fistula and findings were normal.

The vaginal stone was confirmed to be largely comprised of calcified material; basophilic fibrillary basophilic clumps admixed with refractile suture material and rare detached squamous epithelium. Gram and Grocott section confirmed bacteria morphologically compatible with Actinomyces species.
The patient was reviewed at clinic 6 weeks later and had made an uneventful recovery with good wound healing.

\section{Discussion}

Vaginal stone is uncommon and may be primary or secondary. Primary stone formation occurs due to urinary stasis in the vagina while secondary formation is due to crystallisation of urine around a foreign body. ${ }^{1}$ To date there have been few case reports of vaginal stone formation following mid-urethral or transvaginal mesh procedures. ${ }^{2-4}$ The most recent in 2017 reported vaginal stone formation secondary to vaginal mesh exposure 7 years previously. ${ }^{5}$

A mid-urethral sling is regarded as the gold standard' in treating urinary stress incontinence and is a very common procedure. Mesh exposure or even vaginal stones may be increasingly encountered. It has been postulated that urine leakage from the bladder along the remaining tape results in precipitation of calcium and other minerals around the tape with eventual creation of a vaginal stone. ${ }^{2}$ Although this procedure is commonly performed, there are no guidelines or consensus on the length or frequency
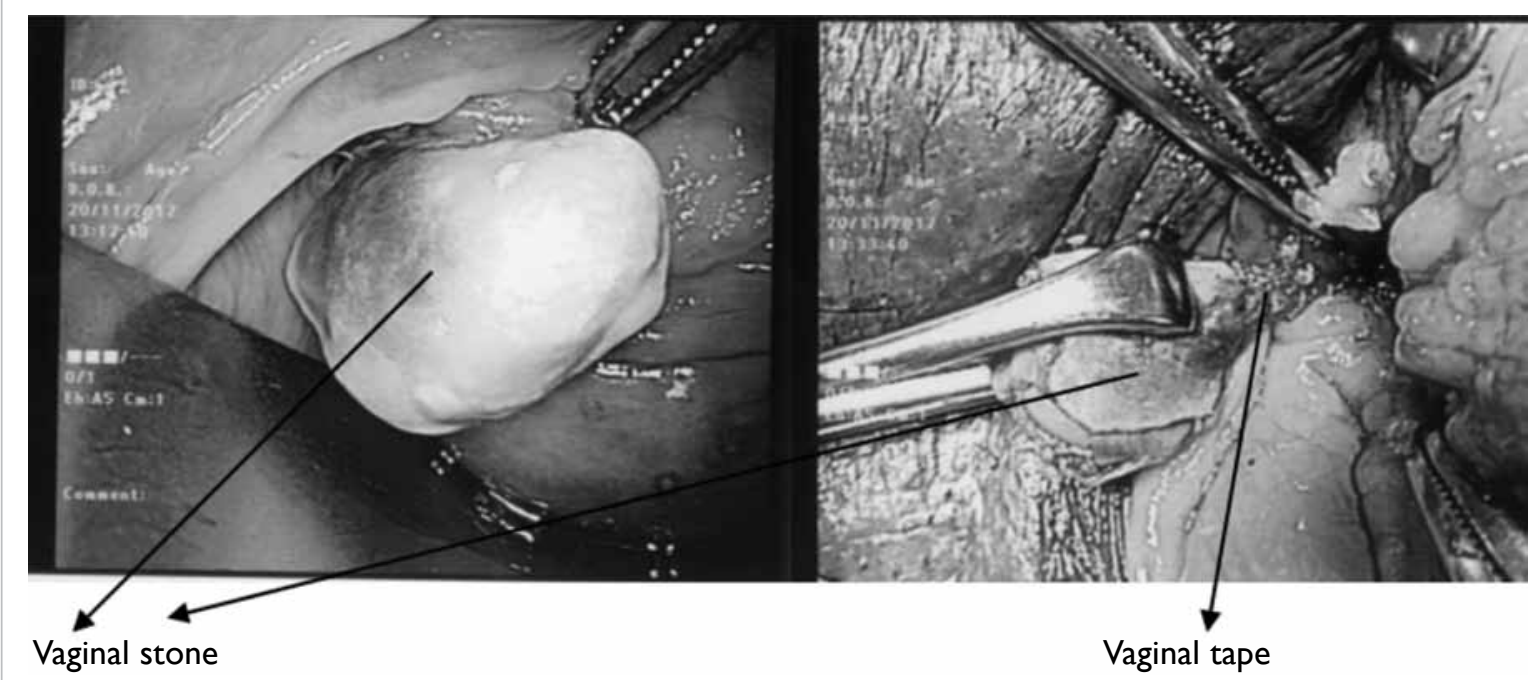

FIG. Vaginal stone and the relationship of the stone with the mid-urethral tape 
of postoperative follow-up examinations. The 2019 National Institute for Health and Care Excellence guidelines on management of urinary incontinence in women suggest a follow-up appointment within 6 months to all women who have undergone continence surgery. ${ }^{6}$ Although case reports of this kind of secondary vaginal stone are limited, surgeons should be aware that such complications can appear many years after operation. More stringent followup should be considered for these patients.

\section{Author contributions}

The author contributed to the concept of study, acquisition and analysis of data, drafting of the article, and had critical revision for important intellectual content. The author had full access to the data, contributed to the study, approved the final version for publication, and takes responsibility for its accuracy and integrity.

\section{Conflicts of interest}

The author has disclosed no conflicts of interest.

\section{Funding/support}

This case report received no specific grant from any funding agency in the public, commercial, or not-for-profit sectors.

\section{Ethics approval}

The patient was treated in accordance with the Declaration of Helsinki. The patient provided informed consent for all procedures.

\section{References}

1. Plaire JC, Snodgrass WT, Grady RW, Mitchell ME. Vaginal calculi secondary to partial vaginal outlet obstruction in paediatric patients. J Urol 2000;164:132-3.

2. Zilberlicht A, Feiner B, Haya N, Auslender R, Abramov Y. Surgical removal of a large vaginal calculus formed after a tension-free vaginal tape procedure. Int Urogynecol J 2016;77:1771-2.

3. Ismail SI, Gasson JN. Vaginal stone formation on top of recurrent tension-free vaginal tape mesh erosion. J Obstet Gynaecol 2014;34:452-3.

4. Winkelman WD, Rabban JT 3rd, Korn AP. Vaginal calculus in a woman with mixed urinary incontinence and vaginal mesh exposure. Female Pelvic Med Resconstr Surg 2016;22:e20-1.

5. Griffiths KM, Towers GD, Yaklic JL. Vaginal urinary calculi formation secondary to vaginal mesh exposure with urinary incontinence. Case Rep Obstet Gynecol 2017;2017:8710315.

6. Urinary incontinence and pelvic organ prolapse in women: management. NICE guideline [NG123]. April 2019.

\section{CORRECTION}

\section{Correction to: Radiological progression of penicillin-sensitive Staphylococcus aureus aortitis}

In this report by S Zheng (Hong Kong Med J 2019 Aug;25(4):329.e1-2, 10.12809/hkmj187616), the text incorrectly stated that the patient was admitted to Sengkang General Hospital, Singapore. In fact, the patient was admitted to Singapore General Hospital, Singapore, and this was the author's affiliation at that time.

The online article at www.hkmj.org has been corrected. 